\title{
Species diversity and insecticide resistance within the Anopheles hyrcanus group in Ubon Ratchathani Province, Thailand
}

\author{
Anchana Sumarnrote ${ }^{1}$, Hans J. Overgaard ${ }^{1,2,3}$, Vincent Corbel ${ }^{1,2}$, Kanutcharee Thanispong ${ }^{4}$, \\ Theeraphap Chareonviriyaphap ${ }^{5}$ and Sylvie Manguin ${ }^{6 *}$ (D)
}

\begin{abstract}
Background: Members of the Anopheles hyrcanus group have been incriminated as important malaria vectors. This study aims to identify the species and explore the insecticide susceptibility profile within the Anopheles hyrcanus group in Ubon Ratchathani Province, northeastern Thailand where increasing numbers of malaria cases were reported in 2014.
\end{abstract}

Methods: Between 2013 and 2015, five rounds of mosquito collections were conducted using human landing and cattle bait techniques during both the rainy and dry seasons. Anopheles mosquitoes were morphologically identified and their insecticide susceptibility status was investigated. Synergist bioassays were carried out with An. hyrcanus (s.l.) due to their resistance to all insecticides. An ITS2-PCR assay was conducted to identify to species the Hyrcanus group specimens.

Results: Out of 10,361 Anopheles females collected, representing 18 taxa in 2 subgenera, $71.8 \%$ were morphologically identified as belonging to the Hyrcanus Group (subgenus Anopheles), followed by An. barbirostris group (7.9\%), An. nivipes (6.5\%), An. philippinensis (5.9\%) and the other 14 Anopheles species. Specimens of the Hyrcanus Group were more prevalent during the rainy season and were found to be highly zoophilic. Anopheles hyrcanus (s.l.) was active throughout the night, with an early peak of activity between 18:00 h and 21:00 h. ITS2-PCR assay conducted on 603 DNA samples from specimens within the Hyrcanus Group showed the presence of five sisters species. Anopheles peditaeniatus was the most abundant species $(90.5 \%, n=546)$, followed by An. nitidus ( $4.5 \%, n=27)$, An. nigerrimus $(4.3 \%, n=26)$, An. argyropus $(0.5 \%, n=3)$, and An. sinensis $(0.2 \%, n=1)$. All An. hyrcanus (s.l.) specimens that were found resistant to insecticides (deltamethrin $0.05 \%$, permethrin $0.75 \%$ and DDT $4 \%$ and synergist tests) belonged to An. peditaeniatus. The degree of resistance in An. peditaeniatus to each of these three insecticides was approximately 50\%. Addition of PBO (Piperonyl butoxide), but not DEF (S.S.S-tributyl phosphotritioate), seemed to restore susceptibility, indicating a potential role of oxidases as a detoxifying enzyme resistance mechanism.

Conclusions: A better understanding of mosquito diversity related to host preference, biting activity and insecticide resistance status will facilitate the implementation of locally adapted vector control strategies.

Keywords: Anopheles hyrcanus, Malaria vectors, Species diversity, Insecticide resistance, Ubon Ratchathani Province, Thailand

\footnotetext{
*Correspondence: sylvie.manguin@ird.fr

${ }^{6}$ HydroSciences Montpellier (HSM), Institut de Recherche pour le Développement (IRD), CNRS, Université Montpellier, Montpellier, France

Full list of author information is available at the end of the article
}

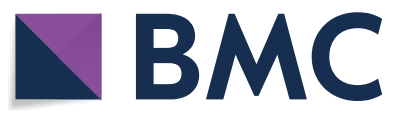

(c) The Author(s) 2020. This article is licensed under a Creative Commons Attribution 4.0 International License, which permits use, sharing, adaptation, distribution and reproduction in any medium or format, as long as you give appropriate credit to the original author(s) and the source, provide a link to the Creative Commons licence, and indicate if changes were made. The images or other third party material in this article are included in the article's Creative Commons licence, unless indicated otherwise in a credit line to the material. If material is not included in the article's Creative Commons licence and your intended use is not permitted by statutory regulation or exceeds the permitted use, you will need to obtain permission directly from the copyright holder. To view a copy of this licence, visit http://creativeco mmons.org/licenses/by/4.0/. The Creative Commons Public Domain Dedication waiver (http://creativecommons.org/publicdomain/ zero/1.0/) applies to the data made available in this article, unless otherwise stated in a credit line to the data. 


\section{Background}

In the southern Palearctic and Oriental regions, the Hyrcanus Group of mosquitoes is a complex species assemblage belonging to the Myzorhynchus Series of the subgenus Anopheles (Diptera: Culicidae), which comprises 26 closely related species [1, 2]. Several species of this group have previously been identified as active malaria vectors transmitting Plasmodium vivax, as well as lymphatic filariasis caused by Brugia malayi and Wuchereria bancrofti in many countries of South, Southeast and East Asian regions [3, 4]. Within the Hyrcanus Group, Anopheles sinensis is considered the most efficient vector of these human parasitic agents, especially $P$. vivax, in China and Korea, and P. malariae in Vietnam [4-11]. Anopheles peditaeniatus has been reported as a secondary vector of Japanese encephalitis virus in China and India [12-14]. In southern Vietnam, An. nimpe transmits both $P$. falciparum and $P$. vivax $[6,15,16]$. Anopheles nigerrimus was incriminated as a suspected vector of $P$. falciparum and $P$. vivax in Bangladesh [17] and as a secondary or incidental vector of W. bancrofti in Asian regions [3], although in China this species is of primary importance in the transmission of W. bancrofti [18] and the arthropod roundworm Romanomermis jingdeensis [19]. In central China, An. lesteri (syn. An. anthropophagus), which was considered as the primary malaria vector [20], is disappearing for the benefit of An. sinensis, which is the predominant species in southwestern China [10]. In addition, the species of the Hyrcanus Group are also considered as economic pests of cattle due to their vicious biting behavior and ability to transmit cervid filariae of the genus Setaria [21, 22].

In Thailand, at least eight species of the Hyrcanus Group have been reported so far. These include: three species of the Lesteri Subgroup (An. crawfordi, An. paraliae and An. peditaeniatus), three species of the Nigerrimus Subgroup ( $A n$. nigerrimus, $A n$. nitidus and $A n$. pursati) and two unassociated species (An. argyropus and An. sinensis) [23, 24]. Seven of these species are widely distributed throughout the country, while An. paraliae is restricted to coastal areas of peninsular and southeastern Thailand [24]. Anopheles argyropus, An. nigerrimus, An. peditaeniatus, and An. sinensis are the most abundant of the Hyrcanus species and are widely distributed in Thailand where they are found in valleys and mountainous areas [24]. Anopheles nitidus and An. crawfordi are frequent in forested areas. Anopheles paraliae larvae are normally developing in shaded semi- to permanent brackish water but not in rice fields, contrasting with immature stages of most species of the Hyrcanus Group, which are usually observed in rice fields, marshy and swampy areas, ponds, and other similar habitats with emergent vegetation [24]. Among the eight An. hyrcanus (s.l.) species recorded in Thailand, An. sinensis, An. nigerrimus and An. peditaeniatus are suspected as vectors of $P$. vivax [22, 25, 26]. Rattanarithikul et al. [26] have already detected the circumsporozoite antigen of P. vivax in An. hyrcanus (s.l.) specimens. Moreover, experimental infections of the Thai An. hyrcanus (s.l.) species (An. argyropus, An. crawfordi, An. nigerrimus, An. peditaeniatus and $A n$. pursati) with the nocturnally subperiodic $B$. malay $i$ filaria have been successfully conducted in the past, thus showing the vectorial potential of these mosquitoes for the transmission of this parasite [27].

Adult females within the Hyrcanus Group stand out from other Anopheles groups by the presence of basal pale scales on their antennae (usually four scales) and a tuft of dark scales on each side of the clypeus. In contrast, adult females of the Hyrcanus Group are difficult to distinguish due to their overlapping morphological characters, particularly when they occur in sympatry, thus leading to misidentification. In the field, ParedesEsquivel et al. [28] reported frequent misidentification of An. hyrcanus (s.l.) specimens with members of the An. barbirostris group, which also belongs to the Myzorhynchus Series. Mosquitoes of the two groups share some similar morphological characteristics such as a humeral crossvein composed of a remigium patch with dark scales and narrow apical pale bands on the midtarsi, comparable wing patterns, narrow apical fringe spot on the wings, narrow tarsal bands, and highly variable hindtarsal banding patterns [23]. These characteristics, as well as loss or damage of mosquito samples during field activities, are the leading causes of misidentification that may skew data on the current distribution of Anopheles vectors across the country and ultimately reduce the benefits of vector control approaches. Accurate identification of Anopheles mosquitoes is therefore needed mainly because only a few species play an important role in malaria transmission and targeting the specific species is crucial for implementation of effective vector control measures.

The second internal transcribed spacer (ITS2) of nuclear ribosomal DNA and the cytochrome $c$ oxidase subunits 1 and 2 ( $\operatorname{cox} 1$ and $\operatorname{cox} 2$ ) of the mitochondrial DNA have been widely used to distinguish species of the Hyrcanus Group [7, 23, 25, 29]. Due to its high inter- and intra-specific variability, studies on the polymorphism of the ITS2 region have been helpful for the development of polymerase chain reaction (PCR) DNA-based assays in order to specifically identify cryptic and isomorphic species [30,31]. The ITS2 region is relatively short in length (generally less than $1 \mathrm{~kb}$ ) and highly conserved, which are suitable criteria for the design of universal primers allowing its fast amplification and sequencing [32]. Based on ITS2 polymorphisms, Hempolchom et al. [23] have 
designed specific primer sequences, which were successfully used in a single-round multiplex PCR for the identification of Anopheles species within the Hyrcanus Group.

In 2014, a malaria outbreak occurred in Ubon Ratchathani Province, located in the northeast of Thailand along the Cambodia and Lao PDR borders [33]. The number of malaria cases increased from 1130 in 2013 to 7708 cases in 2014, a seven-fold increment accounting for $26 \%$ of the total number of reported malaria cases in Thailand that year. Regarding the malaria transmission data in Thailand, only few entomological surveys have been conducted in the eastern part of the country. Consequently, little is known concerning the current distribution of Anopheles vectors in this malaria endemic area [34].

In addition, insecticide resistance in malaria vectors threatens malaria control efforts, which generates a growing concern in many countries. Insecticide resistance in some Anopheles mosquito have been previously reported in the Greater Mekong Subregion (GMS) countries. Van Bortel et al. [35] reported resistance to lambda-cyhalothrin and suspected resistance to alpha-cypermethrin in $A n$. dirus (sensu stricto) in Vietnam. Anopheles epiroticus was reported to be resistant to all pyrethroid insecticides in the Mekong delta, while suspected resistance to DDT was found in Ho Chi Minh City [5]. Anopheles minimus (sensu lato) populations was found resistant to pyrethroids in northern Vietnam and to DDT in western Cambodia and northern Vietnam [35]. Resistance to DDT and pyrethroids was found in Anopheles vagus from Vietnam and Cambodia. In the northern part of Thailand, DDT resistance was detected in An. dirus (s.l.), An. minimus (s.l.) and An. maculatus. Resistance to permethrin was found in a population of An. minimus (s.l.) from northern Thailand [36]. Between 2013 and 2015, Sumarnrote et al. [37] conducted entomological surveys in order to assess species diversity and insecticide resistance to Anopheles collected in six sites along the Thai-Lao border. Our findings showed that $A n$. hyrcanus group was the most represented taxon with a total of 7442 specimens corresponding to $72.5 \%$ of the total Anopheles population. Also, insecticide susceptibility assays were performed and we observed resistance to insecticides in most specimens collected ( 45 to $87 \%$ mortality to deltamethrin $0.05 \%$, permethrin $0.75 \%$ and DDT $4 \%$ ). It was relevant to address whether resistance occurred in potential malaria vectors. In order to complement the information on malaria transmission in potential endemic areas at high risk of outbreaks in Thailand, this present study aimed at identifying members of the Hyrcanus Group to specieslevel and explore the insecticide susceptibility profiles of An. hyrcanus (s.l.) mosquitoes in six locations across the Ubon Ratchathani Province.

\section{Methods}

\section{Study sites}

Mosquito collections were carried out in six sites (5 villages and 1 rubber plantation) located in four districts along the Thai-Lao border in Ubon Ratchathani Province (Fig. 1). The six surveyed sites included Pakla $\left(15^{\circ} 38^{\prime} 46.0^{\prime \prime} \mathrm{N}\right.$, $\left.105^{\circ} 37^{\prime} 59.1^{\prime \prime} \mathrm{E}\right)$ and Talong $\left(15^{\circ} 24^{\prime} 20.4^{\prime \prime} \mathrm{N}, 105^{\circ} 33^{\prime} 46.7^{\prime \prime} \mathrm{E}\right)$ villages located in the Khong Chiam district, Nongmek $\left(14^{\circ} 35^{\prime} 37.1^{\prime \prime} \mathrm{N}, 105^{\circ} 22^{\prime} 33.5^{\prime \prime} \mathrm{E}\right)$ and Sanghom $\left(14^{\circ} 33^{\prime} 42.4^{\prime \prime} \mathrm{N}\right.$, $\left.105^{\circ} 21^{\prime} 47.5^{\prime \prime} \mathrm{E}\right)$ villages in the Buntharik district, Payaka $\left(14^{\circ} 58^{\prime} 49.8^{\prime \prime} \mathrm{N}, 105^{\circ} 31^{\prime} 04.8^{\prime \prime} \mathrm{E}\right)$ village in the Sirindhom district and the rubber plantation $\left(14^{\circ} 32^{\prime} 57.2^{\prime \prime} \mathrm{N}\right.$, $105^{\circ} 16^{\prime} 44.4^{\prime \prime} \mathrm{E}$ ) in the Nachaluay district. The selection of surveyed sites was based on malaria incidence data in the province between 2012 and 2015 [33]. During this 3 yearperiod, a total of 128,293 malaria cases were reported in Thailand with 14,079 (11\%) cases recorded in the Ubon Ratchathani Province. Of these 14,079 cases, the Buntharik district had 6116 cases, followed by Nachalauy (4251 cases) and Nam Yuen (1593 cases), Si Mueang Mai (576 cases), Sirindhorn (357 cases), Det Udom (288 cases), and Khong Chiam (274 cases) [33].

\section{Mosquito collections and species identification}

In each site, mosquito collections were conducted between September 2013 and September 2015 as described by Marasri et al. [38] and Sumarnrote et al. [37]. Collection periods are shown in Table 1. In brief, mosquitoes were collected during both dry (March) and rainy seasons (from September to October) over a two-year period using the humanlanding catch (HLC) technique and cow bait collections $(\mathrm{CBC})$ to determine the vector abundance and composition [39]. A separate collection for the susceptibility test along with the synergist test was conducted during the rainy season (September 2015). For every round of collection, four households and one cow fence were used respectively for HLCs (both indoor and outdoor) and CBC. The same collection points (households and cow fences) were maintained during the entire period of collection. Mosquitoes were individually placed in glass tubes and kept for morphological identification [24] and subsequent bioassays [40]. Then, specimens were preserved in microtubes at $-20{ }^{\circ} \mathrm{C}$ and brought back to the laboratory. Anopheles mosquitoes belonging to the Hyrcanus Group were sent to the UMR-HSM Laboratory at the Institut de Recherche pour le Développement, Montpellier, France, for molecular species identification using allele-specific multiplex PCR assays [23].

Insecticide susceptibility of An. hyrcanus (s.l.) mosquitoes According to our previous published study [37], susceptibility status to deltamethrin $(0.05 \%)$, permethrin $(0.75 \%)$ and DDT (4\%) was investigated following WHO guidelines. 
Bioassays with the synergists PBO 4\% and DEF $0.25 \%$ were carried out in An. hyrcanus (s.l.) to address the role of detoxifying enzymes in insecticide resistance. Knock-down resistance $(k d r)$ was carried out to detect a fragment of the voltage-gated sodium channel gene substitutions at position 1014 in resistant mosquitoes.

\section{Extraction of mosquito genomic DNA}

Genomic DNA was individually extracted from adult female An. hyrcanus (s.l.) using the whole insect according to previous protocols $[41,42]$. Specifically, individual mosquitoes were placed into a DNA extraction tube and homogenized with $50 \mathrm{ml}$ of extraction buffer containing $0.2 \mathrm{M}$ sucrose, $0.1 \mathrm{M}$ Tris- $\mathrm{HCl}$ at $\mathrm{pH}$ 8.0, $50 \mathrm{mM}$ EDTA (pH 8 ) and $0.5 \%$ SDS. Thereafter samples were incubated at 65 ${ }^{\circ} \mathrm{C}$ for $30 \mathrm{~min}$. A volume of $11 \mu \mathrm{l}$ of $5 \mathrm{mM}$ KOAc ( $\left.\mathrm{pH} 9.0\right)$ was added in each tube and placed on ice for $30 \mathrm{~min}$. After centrifugation for $20 \mathrm{~min}$ at $12,000 \times \mathrm{rpm}$, the supernatant was transferred into a clean tube. A volume of $100 \mu \mathrm{l}$ of absolute ethanol was added and the samples were placed at $4{ }^{\circ} \mathrm{C}$ for $10 \mathrm{~min}$. Samples were centrifuged at $12,000 \times \mathrm{rpm}$ at $4{ }^{\circ} \mathrm{C}$ for $20 \mathrm{~min}$ and the supernatant discarded. The pellet was cleaned with $150 \mu \mathrm{l}$ of $70 \%$ ethanol and centrifuged at $12,000 \times \mathrm{rpm}$ for $5 \mathrm{~min}$ at $4{ }^{\circ} \mathrm{C}$. The supernatant was discarded and the previous step was repeated with absolute ethanol and centrifugation at $12,000 \times \mathrm{rpm}$ for $5 \mathrm{~min}$ at 4 ${ }^{\circ} \mathrm{C}$. The resultant pellet was dried at room temperature for $30 \mathrm{~min}$ before being re-suspended in $100 \mu \mathrm{l}$ of DNase/ RNase-Free Distilled Water and stored at $-20{ }^{\circ} \mathrm{C}$ for further analyses.

\section{Molecular identification of An. hyrcanus sibling species by allele-specific PCR}

The extracted DNA was used for species molecular identification using an allele-specific multiplex PCR assay (AS-PCR) examining the ITS2 region of the rDNA. The universal ITS2 forward primer (ITS2A) and eight speciesspecific reverse primers were used to selectively amplify genomic DNA of An. hyrcanus sibling species as described by Hempolchom et al. [23]. The PCR reaction was performed in a total volume of $20 \mu \mathrm{l}$, composed of $5 \times$ Tfi PCR reaction buffer (Invitrogen, Villebon-sur-Yvette, France), $50 \mathrm{mM} \mathrm{MgCl}_{2}$ (Invitrogen), $10 \mathrm{mM}$ dNTPs (mix), and Tfi DNA polymerase (Taq) (5U/ $\mu$; Invitrogen). Thermal conditions were as follows, an initial denaturation temperature of $94{ }^{\circ} \mathrm{C}$ for $1 \mathrm{~min}, 30$ cycles of $94{ }^{\circ} \mathrm{C}$ for $30 \mathrm{~s}, 55^{\circ} \mathrm{C}$ for $30 \mathrm{~s}$ for the annealing temperature, an extension phase at $72{ }^{\circ} \mathrm{C}$ for $1 \mathrm{~min}$ and a final extension step at $72{ }^{\circ} \mathrm{C}$ for $5 \mathrm{~min}$.

The amplified PCR products were subjected to electrophoresis in 2\% agarose gels stained with GelRed (Biotium Inc, Fremont, CA, USA). The expected band sizes of the PCR amplicons for the different species are described by Hempolchom et al. [23]. Moreover, 20 PCR amplicons of different species were sent for sequencing and assessed by Genewiz (Paris, France) using the ITS2 universal primer (5'-TGT GAA CTG CAG GAC ACA T-3') to confirm species identifications. Each sequence was checked and cleaned manually using the BioEdit software version 7.1.9 [43].

\section{Data analysis}

Percentage of zoophilic and anthropophilic behavior in $A n$. hyrcanus group was assessed by the abundance of mosquito samples collected from CBC and HLC, respectively. The difference in the mean number of specimens of the An. hyrcanus group captured during the rainy and dry seasons was analyzed by non-parametric MannWhitney U-test and statistical significance was designated at $0.05 \%(P$-value $<0.05)$. Statistical analyses were performed using the Statistical Package for Social Science (SPSS) version 24.0 (SPSS Inc., Chicago, IL, USA).

\section{Results}

Overall, 10,361 females Anopheles mosquitoes were caught in the six villages over a 2-year (from September 2013 to September 2015) period of collection [38]. Of these, 7,442 specimens were morphologically identified as belonging to the An. hyrcanus group, thus corresponding to $71.8 \%$ of the total Anopheles fauna collected. Specimens of the An. hyrcanus group showed a zoophilic biting behavior with $98.7 \%$ collected on cow bait. Numbers of An. hyrcanus group collected on human and cattle bait from each site are presented in Fig. 2. The abundance of the Hyrcanus specimens with a brief description of the surrounding environment is presented in Additional file 1: Table S1. Anopheles hyrcanus (s.l.) was significantly $(P<0.001)$ more abundant during the rainy season (99.4\%, 7395/7442) than during the dry season with only 47 specimens $(0.6 \%)$. No An. hyrcanus was collected in Pakla, Talong and Payaka villages during the dry seasons (March 2014 and March 2015), whereas only a few specimens were collected in Nongmek $(n=16)$ and Sanghom $(n=25)$ villages, and in the rubber plantation $(n=6)$ of the Nachaluay District (Table 1 ). The biting activity of the An. hyrcanus group was highest in the early evening during 18:00-21:00 h, and gradually declined thereafter (Fig. 3).

\section{Insecticide susceptibility tests and molecular species identification}

Following insecticide susceptibility tests from our previous published study [37], a total of 603 specimens of the $A n$. hyrcanus group representing different insecticide susceptibility status were selected and identified 
to species by a PCR-based assay. Samples consisted of mosquitoes that were either resistant $(n=230)$ or susceptible $(n=264)$ to various insecticides (Table 2$)$.

The PCR identification of 603 randomly selected samples identified as An. hyrcanus (s.l.) revealed the presence of five sibling species. Anopheles peditaeniatus was predominant $(90.5 \%, 546 / 603)$ followed by $A n$. nitidus ( $n=27,4.5 \%)$, An. nigerrimus ( $n=26,4.3 \%)$, An. argyropus $(n=3,0.5 \%)$, and $A n$. sinensis $(n=1,0.2 \%)$. The highest abundance and species diversity were found in the village of Sanghom where all five Anopheles species were recorded (Table 3). In Pakla, Talong and Payaka villages, only $A n$. peditaeniatus was found, while An. peditaeniatus, An. nigerrimus, An. nitidus in addition to $A n$. argyropus were respectively recorded in Nachaluay and Nongmek villages (Table 3 ).

Metabolic resistance mechanism in Anopheles hyrcanus (s.l.) was assessed by using synergists. In our previous publication, pre-exposure of An. hyrcanus (s.l.) to PBO $4 \%$ caused a significant increase of approximately $50 \%$ in mortality, whereas a slight increase of pyrethroid mortality was found in presence of DEF $0.25 \%$ [37]. Out of 564 specimens selected from bioassay tested with different insecticides as well as from the synergist tests, 230 resistant specimens were all identified as An. peditaeniatus by molecular assay $(49.3 \%, 230$ resistant out of 467 tested), while susceptible specimens were identified as An. peditaeniatus ( $n=237)$, An. nigerrimus ( $n=$ $16)$ and An. nitidus $(n=9)$, An. argyropus $(n=1)$ and An. sinensis $(n=1)$ (Table 4$)$.

\section{Discussion}

Knowledge of the density and species composition of mosquito vectors is crucial for determining the distribution and potential risk of vector-borne diseases transmission. Previous findings showed that An. hyrcanus group is predominant along the Thai-Lao border of Ubon Ratchathani Province, accounting for $71.8 \%$ of all Anopheles species collected [38].

In this study, among the five species of the Hyrcanus Group identified, An. peditaeniatus was most abundant $(90.5 \%, n=546)$. This species is widely distributed in Thailand [24]. Gingrich et al. [44] reported that An. peditaeniatus was primarily caught during and after the rainy season and the biting peak was usually before midnight. The detection of the Plasmodium circumsprozoite antigen in An. peditaeniatus salivary glands using the enzyme-linked immunoassay (ELISA) raised up the potential implication of this species in malaria transmission across this region [44]. In Indonesia, An. peditaeniatus was found positive for $P$. falciparum circumsporozoite proteins (CSP) by testing heads or thoraces using ELISA [45]. St Laurent et al. [46] reported that one specimen of An. peditaeniatus collected in Cambodia was infected with $P$. falciparum using a nested PCR assay. Moreover, an An. peditaeniatus/Brugia malayi experimental model showed high susceptibility rate (ranging from 70 to $100 \%)$ of the vector to this microfilaria [27]. In addition, An. peditaeniatus is considered as a secondary vector of Japanese encephalitis virus in China and India [12, 14]. Although An. peditaeniatus is abundant and widely distributed throughout Thailand, its vectorial role remains uncertain and needs to be elucidated. Especially important for future studies will be to apply molecular assays to identify this species, as well as the other members of the Hyrcanus Group for precisely determining the role and behavior of each encountered member.

Host-seeking and biting preferences are other important indicators for assessing the role of Anopheles mosquitoes in malaria transmission. Our results showed that An. hyrcanus (s.l.) populations, specifically $A n$. peditaeniatus (90.5\%) have a high preference for cattle compared to humans, and therefore can be considered as highly zoophilic. However, morphological characters had solely been used for species identification, thus possible misidentifications could have occurred due to the close relationship and overlapping characters of the sibling species within the Hyrcanus Group. Previous studies on An. peditaeniatus in Thailand confirm the zoophilic biting behavior [22, 47]. It has also been demonstrated that some Anopheles species may shift from zoophilic to anthropophilic behavior when the number of livestock decreases [48]. Some extrinsic parameters, such as local rainfall, season, latitude, deforestation, food source scarcity, habitat destruction and the use of insecticides, which vary accordingly to locations, may also impact the host preference and their resting behavior [49-53]. Large land-use changes have occurred in Ubon Ratchathani with severe deforestation for rice cultivation and conversion from rice paddy to rubber plantations that could have possibly influenced

(See figure on next page.)

Fig. 1 Collection sites located along on the Thailand-Laos border: 1, Pakla Village (Khong Chiam District); 2, Talong Village (Khong Chiam District); 3, Payaka Village (Sirindhorn District); 4, Nongmek Village (Buntharik District); 5, Sanghom Village (Buntharik District); and 6, Rubber plantation in Nachaluay District. The pie charts are proportional to the number of specimens collected and the number of species in the An. hyrcanus group identified by PCR 


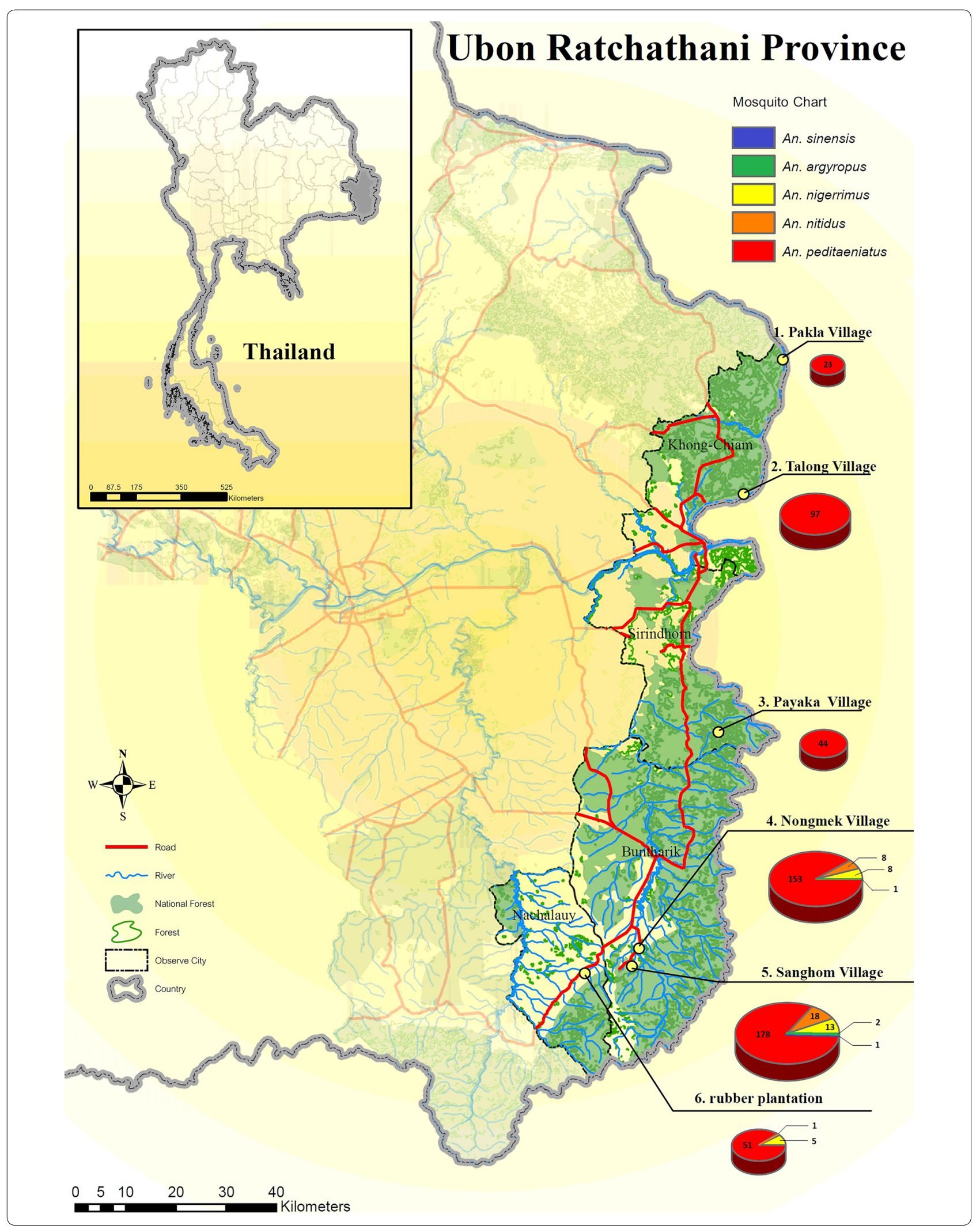


Table 1 Seasonal abundance of the Hyrcanus Group in the six locations in Ubon Ratchathani Province, Thailand

\begin{tabular}{|c|c|c|c|c|c|c|c|c|}
\hline \multirow[t]{4}{*}{ Collection location } & \multirow[t]{4}{*}{ Sub-district } & \multirow[t]{4}{*}{ District } & \multicolumn{6}{|c|}{ Collection periods } \\
\hline & & & Survey 1 & Survey 2 & Survey 3 & Survey 4 & Survey 5 & Total \\
\hline & & & Rainy & Dry & Rainy & Dry & Rainy & \\
\hline & & & Sep-Oct 2013 & Mar-2014 & Sep-Oct 2014 & Mar-2015 & Sep-2015 & \\
\hline Pakla Village & Na Pho Klang & Khong Chiam & 20 & 0 & 131 & 0 & 13 & 164 \\
\hline Talong Village & Huai Pai & Khong Chiam & 187 & 0 & 568 & 0 & - & 755 \\
\hline Payaka Village & Non Ko & Sirindhorn & 77 & 0 & - & - & - & 77 \\
\hline Nongmek Village & Huai Kha & Buntharik & 563 & 13 & 779 & 3 & $--^{a}$ & 1358 \\
\hline Sanghom Village & Huai Kha & Buntharik & 2124 & 14 & 1932 & 11 & $-^{\mathrm{a}}$ & 4081 \\
\hline Rubber plantation & Nachaluay & Nachaluay & - & - & 1001 & 6 & - & 1007 \\
\hline Total per survey ${ }^{b}$ & & & 2971 & 27 & 4411 & 20 & 13 & 7442 \\
\hline
\end{tabular}

a Separate collections of Hyrcanus Group used for insecticide susceptibility test (not part of the regular collections)

b The total number of specimens collected during the rainy (surveys $1,3,5)$ and dry (surveys 2,4$)$ seasons were $7395(99.4 \%)$ and $47(0.6 \%)$, respectively

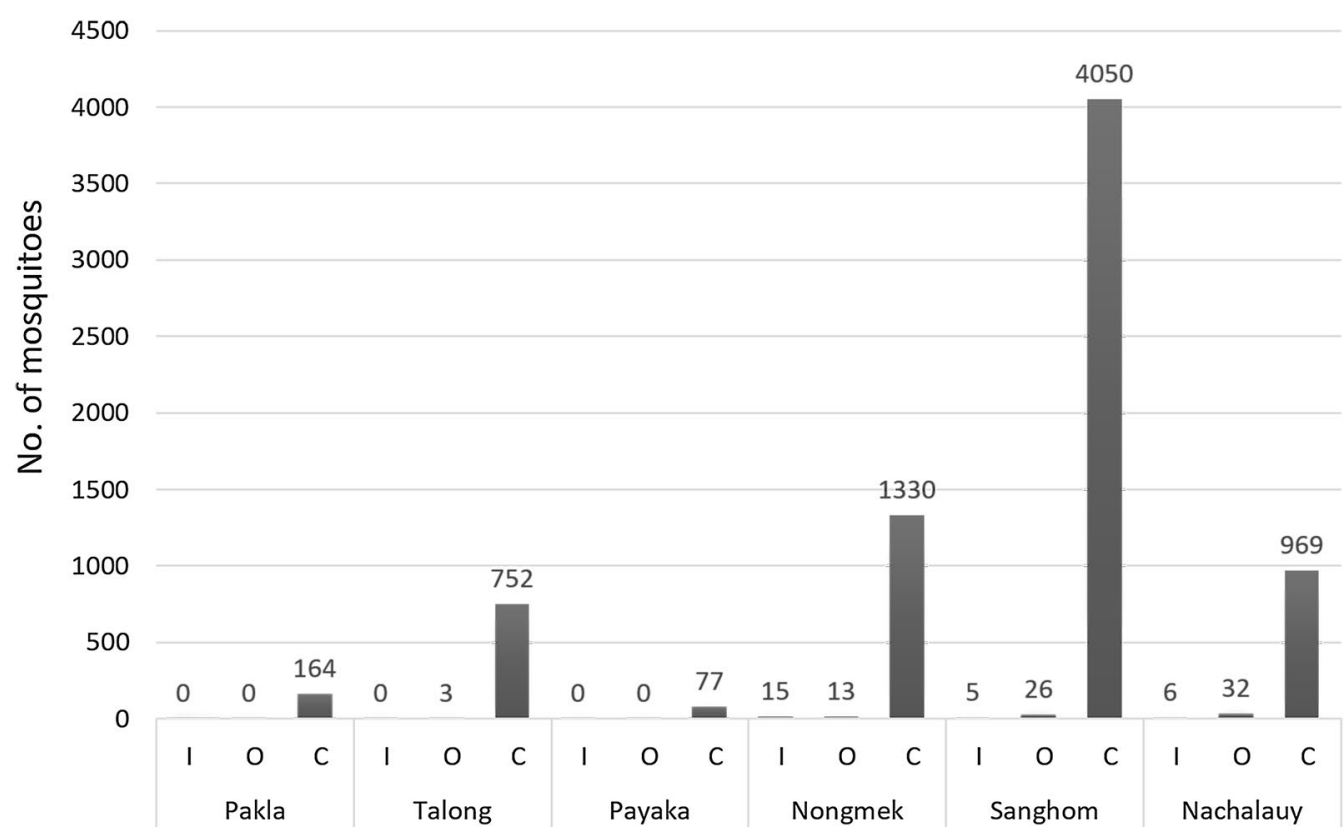

Fig. 2 The number of specimens of the An. hyrcanus group collected on human (indoors and outdoors) and cattle bait. Abbreviations: I, indoors, O; outdoors, C; cow bait

mosquito bionomics [54]. The early biting peak of $A n$. peditaeniatus during dusk hours is of concern because human populations are often found outdoors during these periods and are not protected by bednets.

The results of the present 2-year study showed the very high abundance of specimens of the An. hyrcanus group, largely dominated by An. peditaeniatus, during the rainy season (90.5\%). From previous studies, the preferential breeding habitat of the An. hyrcanus group was rice fields [24], which are widespread in Ubon Ratchathani Province. It could be hypothesized that increased transplanting and maintaining water in rice fields during the rainy season could influence the density of mosquito populations.

Only one An. sinensis specimen was identified by PCR out of the 603 An. hyrcanus (s.l.) tested. This mosquito species is widespread in China and Korea, and is considered an important malaria vector transmitting $P$. vivax $[10,55,56]$. It has been previously proved that An. sinensis populations could exhibit different vectorial capacity depending on their geographic location [56]. In Thailand, An. sinensis plays a minor role in malaria transmission due to its low abundance and restricted spatial distribution although some studies reported that it could 
be experimentally infected with $P$. vivax $[57,58]$. However, further investigations are needed in order to clarify the vectorial role of An. sinensis in Thailand. Furthermore, although relatively low number of the other members of the Hyrcanus Group was found in this study, the role of these species as disease vectors may need to be considered. The role in malaria transmission of $A n$. nitidus, An. nigerrimus and An. argyropus has not been documented so far. Anopheles nigerrimus and An. argyropus were reported as potential vectors of $B$. malayi experimentally, while An. nitidus was found to be a refractory vector [27]. Exploration on the vectorial role of these species could be valuable for malaria control strategies and surveillance.

Out of the 467 specimens of An. peditaeniatus tested in various bioassays (deltamethrin $(0.05 \%)$, permethrin $(0.75 \%)$, DDT (4\%), with or without synergists), approximately half (49\%) were found resistant to at least one of these insecticides. The addition of the PBO (Piperonyl butoxide) synergist, but not DEF (S.S.S-tributyl

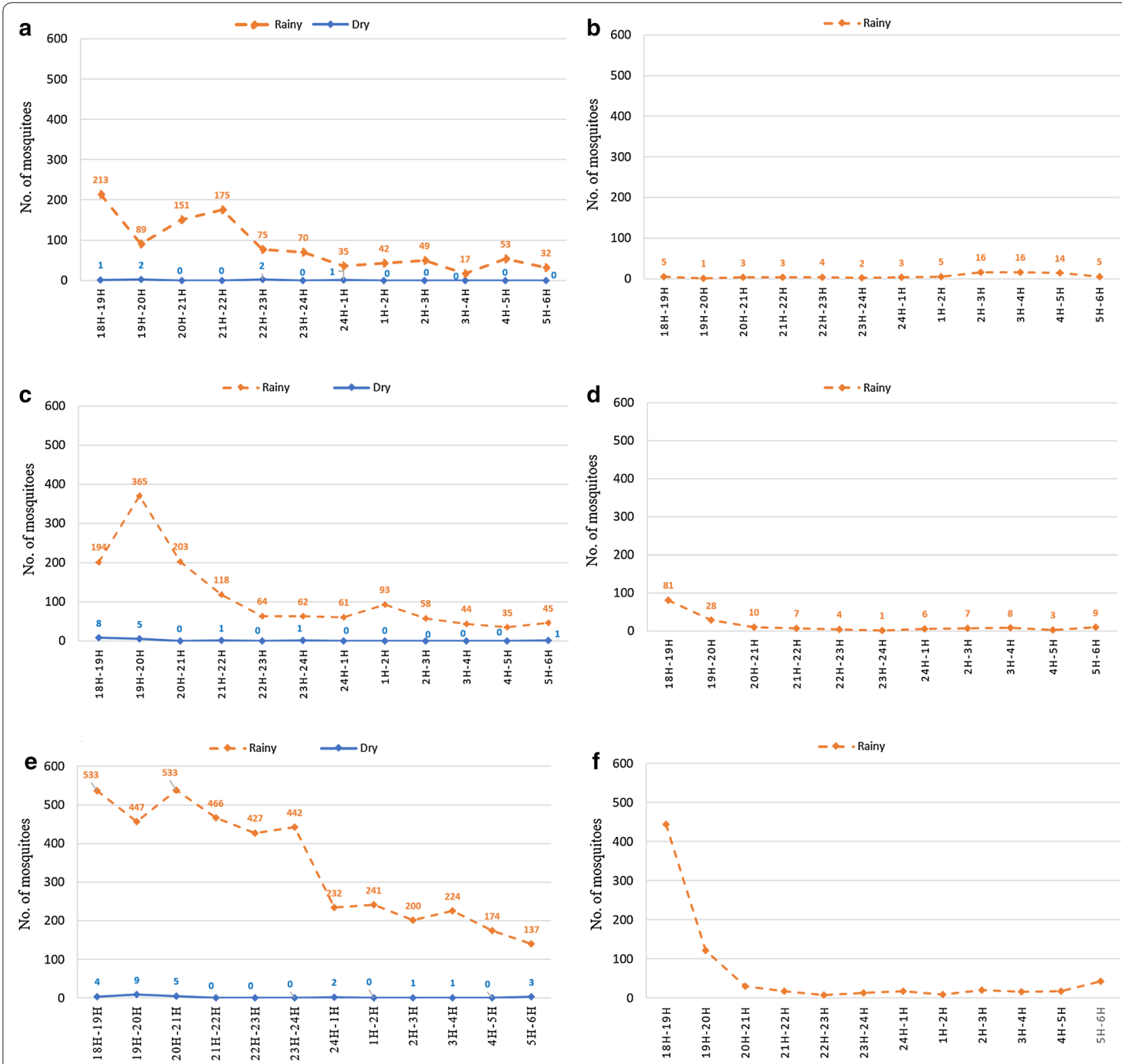

Fig. 3 The number of mosquito specimens in the An. hyrcanus group collected per hour from each collection sites on cattle and human bait during the rainy and dry seasons in Ubon Ratchathani Province, Thailand. a Pakla. b Talong. c Nongmek. d Sanghom. e Payaka. f Rubber plantation in Nachaluay District 
Table 2 Number of specimens selected from the An. hyrcanus group mosquitoes collected in the study sites that were used for PCRbased species identification

\begin{tabular}{|c|c|c|c|c|c|c|c|c|c|c|c|c|}
\hline \multirow[t]{2}{*}{ Villages } & \multirow[t]{2}{*}{ Insecticide } & \multicolumn{2}{|c|}{$\begin{array}{l}\text { Survey } 1 \\
\text { Rainy }\end{array}$} & \multicolumn{2}{|c|}{$\begin{array}{l}\text { Survey } 2 \\
\text { Dry }\end{array}$} & \multicolumn{2}{|c|}{$\begin{array}{l}\text { Survey } 3 \\
\text { Rainy }\end{array}$} & \multicolumn{2}{|c|}{$\begin{array}{l}\text { Survey } 4 \\
\text { Dry }\end{array}$} & \multicolumn{2}{|c|}{$\begin{array}{l}\text { Survey } 5 \\
\text { Rainy }\end{array}$} & \multirow[t]{2}{*}{ Total } \\
\hline & & Alive & Dead & Alive & Dead & Alive & Dead & Alive & Dead & Alive & Dead & \\
\hline \multirow[t]{5}{*}{ Pakla } & No test & 10 & - & - & - & - & - & - & - & 2 & - & 12 \\
\hline & Deltamethrin $0.05 \%$ & - & - & - & - & - & - & - & - & 5 & 6 & 11 \\
\hline & Permethrin $0.75 \%$ & - & - & - & - & - & - & - & - & - & - & 0 \\
\hline & DDT $4 \%$ & - & - & - & - & - & - & - & - & - & - & 0 \\
\hline & Control & - & - & - & - & - & - & - & - & - & - & 0 \\
\hline \multirow[t]{4}{*}{ Talong } & Deltamethrin $0.05 \%$ & 5 & 8 & - & - & 7 & 8 & - & - & & & 28 \\
\hline & Permethrin $0.75 \%$ & 6 & 8 & - & - & 8 & 8 & - & - & & & 30 \\
\hline & DDT 4\% & 7 & 8 & - & - & 8 & 8 & - & - & & & 31 \\
\hline & Control & - & - & - & - & 8 & - & - & - & & & 8 \\
\hline \multirow[t]{4}{*}{ Payaka } & Deltamethrin $0.05 \%$ & 4 & 8 & - & - & & & & & & & 12 \\
\hline & Permethrin $0.75 \%$ & 7 & 8 & - & - & & & & & & & 15 \\
\hline & DDT 4\% & 4 & 8 & - & - & & & & & & & 12 \\
\hline & Control & 5 & - & - & - & & & & & & & 5 \\
\hline \multirow[t]{7}{*}{ Nongmek } & No test & - & - & 6 & - & - & - & 2 & - & - & - & 8 \\
\hline & Deltamethrin $0.05 \%$ & 8 & 5 & - & - & 8 & 8 & - & - & 8 & 8 & 45 \\
\hline & Permethrin $0.75 \%$ & 10 & 8 & - & - & 8 & 8 & - & - & - & - & 34 \\
\hline & DDT $4 \%$ & 9 & 8 & - & - & 8 & 8 & - & - & - & - & 33 \\
\hline & Control & 10 & - & - & - & 7 & - & - & - & 8 & - & 25 \\
\hline & $\mathrm{PBO}+$ deltamethrin $0.05 \%$ & - & - & - & - & - & - & - & - & 3 & 6 & 9 \\
\hline & DEF+deltamethrin $0.05 \%$ & - & - & - & - & - & - & - & - & 8 & 8 & 16 \\
\hline \multirow[t]{9}{*}{ Sanghom } & No test & - & - & 8 & - & - & - & 8 & - & - & - & 16 \\
\hline & Deltamethrin $0.05 \%$ & 8 & 8 & - & - & 6 & 8 & - & - & 9 & 8 & 47 \\
\hline & Permethrin $0.75 \%$ & 8 & 8 & - & - & 7 & 8 & - & - & 8 & 8 & 47 \\
\hline & DDT 4\% & 8 & 8 & - & - & 7 & 8 & - & - & - & - & 31 \\
\hline & Control & 8 & - & - & - & 8 & - & - & - & 8 & - & 24 \\
\hline & $\mathrm{PBO}+$ deltamethrin $0.05 \%$ & - & - & - & - & - & - & - & - & - & 8 & 8 \\
\hline & $\mathrm{DEF}+$ deltamethrin $0.05 \%$ & - & - & - & - & - & - & - & - & 7 & 8 & 15 \\
\hline & $\mathrm{PBO}+$ permethrin $0.75 \%$ & - & - & - & - & - & - & - & - & - & 8 & 8 \\
\hline & DEF + permethrin $0.75 \%$ & - & - & - & - & - & - & - & - & 8 & 8 & 16 \\
\hline \multirow[t]{5}{*}{ Nachaluay } & No test & - & - & - & - & - & - & 3 & - & - & - & 3 \\
\hline & Deltamethrin $0.05 \%$ & & & & & 7 & 7 & - & - & & & 14 \\
\hline & Permethrin $0.75 \%$ & & & & & 8 & 8 & - & - & & & 16 \\
\hline & DDT 4\% & & & & & 8 & 8 & - & - & & & 16 \\
\hline & Control & & & & & 8 & - & - & - & & & 8 \\
\hline Total & & 117 & 93 & 14 & 0 & 121 & 95 & 13 & 0 & 74 & 76 & 603 \\
\hline
\end{tabular}

Notes: Blank cells indicate that no mosquito collections were done during this period in this site

phosphotritioate), seemed to restore susceptibility, indicating a potential role of oxidases as a detoxifying enzyme resistance mechanism [59]. PBO and DEF are widely used as synergists for insecticide treatments. PBO inhibits cytochrome-P450 monooxygenases (multi-function oxidases) that mediates resistance to all classes of insecticides, while DEF is an enzyme inhibitor of esterases [60]. The other tested species in the An. hyrcanus group were susceptible to all three insecticides, although only 27 specimens were tested. A previous study along the Thai-Myanmar border reported $A n$. hyrcanus (s.l.) mortality of $33 \%$ and $48 \%$ to deltamethrin $(0.05 \%)$ and permethrin $(0.75 \%)$, respectively [61]. Two alternate mutations $\mathrm{L} 1014 \mathrm{~S}$ and $\mathrm{L} 1014 \mathrm{~F}$ at residue L1014 of the voltage-gated sodium channel (VGSC) are associated with knockdown resistance in insects including anophelines [62]. The L1014S knockdown resistance $(k d r)$ mutation has also already been detected in $A n$. 
Table 3 Distribution of the Anopheles hyrcanus sibling species per study site based on PCR identification

\begin{tabular}{|c|c|c|c|c|c|c|}
\hline \multirow[t]{2}{*}{ Study site } & \multirow{2}{*}{$\begin{array}{l}\text { Total number of } \\
\text { mosquitoes collected }\end{array}$} & \multicolumn{5}{|c|}{ Number of An. hyrcanus (s.l.) mosquitoes identified by PCR } \\
\hline & & An. peditaeniatus & An. argyropus & An. nigerrimus & An. nitidus & An. sinensis \\
\hline Pakla Village & 164 & 23 & - & - & - & - \\
\hline Talong Village & 755 & 97 & - & - & - & - \\
\hline Payaka Village & 77 & 44 & - & - & - & - \\
\hline Nongmek Village & 1358 & 153 & 1 & 8 & 8 & - \\
\hline Sanghom Village & 4081 & 178 & 2 & 13 & 18 & 1 \\
\hline $\begin{array}{l}\text { Rubber plantation } \\
\text { (Nachaluay) }\end{array}$ & 1007 & 51 & - & 5 & 1 & - \\
\hline Total & 7442 & 546 & 3 & 26 & 27 & 1 \\
\hline
\end{tabular}

Table 4 Species identification of An. hyrcanus group selected from bioassay tests by allele-specific PCR

\begin{tabular}{|c|c|c|c|c|c|c|c|}
\hline \multirow[t]{2}{*}{ Insecticide } & \multirow[t]{2}{*}{ Resistance status } & \multicolumn{5}{|c|}{ Number of specimens } & \multirow[t]{2}{*}{ Total } \\
\hline & & An.peditaeniatus & An. nigerrimus & An. nitidus & An. argyropus & An. sinensis & \\
\hline \multirow[t]{2}{*}{ Deltamethrin 0.05\% } & Susceptible & 75 & 5 & 2 & - & - & 82 \\
\hline & Resistant & 75 & - & - & - & - & 75 \\
\hline \multirow[t]{2}{*}{ Permethrin $0.75 \%$} & Susceptible & 64 & 5 & 3 & - & - & 72 \\
\hline & Resistant & 70 & - & - & - & - & 70 \\
\hline \multirow[t]{2}{*}{ DDT $4 \%$} & Susceptible & 59 & 3 & 2 & - & - & 64 \\
\hline & Resistant & 59 & - & - & - & - & 59 \\
\hline \multirow{2}{*}{$\begin{array}{l}\text { Piperonyl butoxide (PBO) } 4 \%+\text { deltamethrin } \\
0.05 \%\end{array}$} & Susceptible & 12 & 2 & - & - & - & 14 \\
\hline & Resistant & 3 & - & - & - & - & 3 \\
\hline \multirow{2}{*}{ Piperonyl butoxide (PBO) 4\% + permethrin $0.75 \%$} & Susceptible & 6 & - & - & 1 & 1 & 8 \\
\hline & Resistant & - & - & - & - & - & 0 \\
\hline \multirow{2}{*}{$\begin{array}{l}\text { S.S.S-tributyl phosphotritioate (DEF) } 0.25 \%+ \\
\text { deltamethrin } 0.05 \%\end{array}$} & Susceptible & 13 & 1 & 2 & - & - & 16 \\
\hline & Resistant & 15 & - & - & - & - & 15 \\
\hline \multirow{2}{*}{$\begin{array}{l}\text { S.S.S-tributyl phosphotritioate (DEF) } 0.25 \%+ \\
\text { permethrin } 0.75 \%\end{array}$} & Susceptible & 8 & - & - & - & - & 8 \\
\hline & Resistant & 8 & - & - & - & - & 8 \\
\hline Control & & 66 & 2 & 2 & - & - & 70 \\
\hline Total & & 533 & 18 & 11 & 1 & 1 & 564 \\
\hline Resistant & & $230(49.3 \%)$ & 0 & 0 & 0 & 0 & 230 \\
\hline Susceptible & & 237 (50.7\%) & 16 & 9 & 1 & 1 & 264 \\
\hline
\end{tabular}

peditaeniatus [61]. Cross-resistance to DDT and pyrethroids was also observed in An. peditaeniatus from southern Vietnam with high frequency of the L1014F $k d r$ allele and low frequency of the L1014S $k d r$ allele [63]. These findings indicate that this species is under high selection pressure, probably due to the use of pesticides for crop protection.

\section{Conclusions}

In Ubon Ratchathani Province, an unprecedented malaria outbreak occurred in 2014 with nearly 7-fold increment in the total number of malaria cases reported in 2013
[33]. To understand such outbreaks and widely assess the malaria risk in Thailand, it is important to study the spatial distribution of potential vectors and their bionomic traits including vectorial capacity, biting/resting behaviors and preferential breeding sites. Knowledge on these parameters are a prerequisite for implementing the most appropriate and efficient vector control programme. The occurrence and spread of insecticide resistance in malaria vectors, even in secondary or suspected vectors, could potentially change the dynamics of disease transmission and impact the efficacy of vector control interventions. The vectorial role of members of the $A n$. hyrcanus group, as well as other secondary and suspected 
vectors regarding malaria in the Ubon Ratchathani Province and nationwide, needs to be further investigated in order to provide essential information for guiding vectorborne disease monitoring and control campaigns.

\section{Supplementary information}

Supplementary information accompanies this paper at https://doi. org/10.1186/s13071-020-04389-4.

Additional file 1: Table S1. Collection locations of the Hyrcanus Group associated environment in Ubon Ratchathani Province, Thailand.

\section{Abbreviations}

AS-PCR: allele-specific polymerase chain reaction; CBC: cow bait collections; cox1: cytochrome $c$ oxidase subunit 1; cox2: cytochrome $c$ oxidase subunit 2; CSP: circumsporozoite protein; DDT: dichlorodiphenyltrichloroethane; DEF: S.S.S-tributyl phosphotritioate; DNA: deoxyribonucleic acid; dNTP: deoxynucleotide-5'-triphosphate; EDTA: ethylenediaminetetraacetic acid; ELISA: enzyme-linked immunosorbent assay; HLC: human-landing catch; ITS2: internal transcribed spacer 2; kdr: knockdown resistance; $P$ : probability value; PBO: piperonyl butoxide; PCR: polymerase chain reaction; $\mathrm{pH}$ : potential of hydrogen ion; rDNA: ribosomal deoxyribonucleic acid; SPSS: Statistical Package for the Social Sciences; s.l.: sensu lato; s.s.: sensu stricto; Tris-HCl: Tris hydrochloride.

\section{Acknowledgements}

The authors are grateful to the community members, leaders, mosquito collectors and staff who participated and facilitated our surveys. We would like to thank the Institut de Recherche pour le Développement (IRD), Thailand, the Ministry of Public Health, Thailand, and the Institut Pasteur Laos, for their collaboration. We would also like to extend our deepest gratitude to the IRD Laboratory, UMR-HSM, Montpellier, France, for molecular species identification. Thanks also to the Thailand International Development Cooperation Agency (TICA) from the Ministry of Foreign Affairs (through the STOPVEC programme), and the International Research Network Program/Thailand Research Fund (IRN 58000003).

\section{Authors' contributions}

SM, VC, HJO and TC conceived and designed the study. SM and AS carried out laboratory experiments and the molecular genetic studies. AS, KT and $\mathrm{HJO}$ supervised the mosquito collections. AS, SM, HJO, VC and TC analyzed the data and wrote the paper. All authors read and approved the final manuscript.

\section{Funding}

This study was supported by the $5 \%$ Initiative of the Global Funds through the MALVEC research project.

\section{Availability of data and materials}

The datasets used and/or analyzed during the present study are available from the corresponding author upon reasonable request.

\section{Ethics approval and consent to participate}

The activities and protocols used in this study were approved by the Ethics Review Committee for Research Involving Human Research Subjects, Health Science Group, Chulalongkorn University, Bangkok, Thailand (No. 096.1/56). All volunteers signed a written informed consent form before participating in the study. Mosquito collectors received vaccination against Japanese encephalitis (JE) and appropriate medical treatment if they became ill after collections.

\section{Consent for publication}

Not applicable.

\section{Competing interests}

The authors declare that they have no competing interests.

\section{Author details}

${ }^{1}$ Department of Entomology, Faculty of Agriculture at Kamphaeng Saen, Kasetsart University, Kamphaeng Saen Campus, Nakhon Pathom, Thailand. ${ }^{2}$ Maladies Infectieuses et Vecteurs, Ecologie, Génétique, Evolution et Contrôle (MIVEGEC), Institut de Recherche pour le Développement (IRD), University of Montpellier, Montpellier, France. ${ }^{3}$ Faculty of Science and Technology, Norwegian University of Life Sciences, Ås, Norway. ${ }^{4}$ Bureau of Vector-borne Disease, Department of Disease control, Ministry of Public Health, Nonthaburi, Thailand. ${ }^{5}$ Department of Entomology, Faculty of Agriculture, Kasetsart University, Bangkok, Thailand. ${ }^{6}$ HydroSciences Montpellier (HSM), Institut de Recherche pour le Développement (IRD), CNRS, Université Montpellier, Montpellier, France.

Received: 19 June 2020 Accepted: 6 October 2020

Published online: 17 October 2020

\section{References}

1. Ma Y, Xu J. The Hyrcanus group of Anopheles (Anopheles) in China (Diptera: Culicidae): species discrimination and phylogenetic relationships inferred by ribosomal DNA internal transcribed spacer 2 sequences. J Med Entomol. 2005;42:610-9.

2. Harbach R. Mosquito taxonomic inventory. 2017. http://mosquito-taxon omic-inventory.info/sites/mosquito-taxonomic-inventory.info/files/ Anopheles\%20classification_48.pdf. Accessed 15 Jan 2019.

3. Manguin S, Bangs MJ, Pothikasikorn J, Chareonviriyaphap T. Review on global co-transmission of human Plasmodium species and Wuchereria bancrofti by Anopheles mosquitoes. Infect Genet Evol. 2010;10:159-77.

4. Chai JY. Re-emerging Plasmodium vivax malaria in the Republic of Korea. Korean J Parasitol. 1999:37:129-43.

5. Lee HW, Shin EH, Cho SH, Lee HI, Kim CL, Lee WG, et al. Detection of vivax malaria sporozoites naturally infected in anopheline mosquitoes from endemic areas of northern parts of Gyeonggi-do (Province) in Korea. Korean J Parasitol. 2002:40:75-81.

6. Manh CD, Beebe NW, Van VN, Quang TL, Lein CT, Nguyen DV, et al. Vectors and malaria transmission in deforested, rural communities in northcentral Vietnam. Malar J. 2010;9:259.

7. Ngo CT, Harbach RE, Garros C, Parzy D, Le HQ, Manguin S. Taxonomic assessment of Anopheles crawfordi and An. dangi of the Hyrcanus Group of subgenus Anopheles in Vietnam. Acta Trop. 2013;128:623-9.

8. Oh SS, Hur MJ, Joo GS, Kim ST, Go JM, Kim YH, et al. Malaria vector surveillance in Ganghwa-do, a malaria-endemic area in the Republic of Korea. Korean J Parasitol. 2010;48:35-41.

9. Ree HI, Hwang UW, Lee IY, Kim TE. Daily survival and human blood index of Anopheles sinensis, the vector species of malaria in Korea. J Am Mosq Control Assoc. 2001;17:67-72.

10. Zhang S, Guo S, Feng X, Afelt A, Frutos R, Zhou S, et al. Anopheles vectors in mainland China while approaching malaria elimination. Trends Parasitol. 2017:33:889-900.

11. Sinka ME, Bangs MJ, Manguin S, Chareonviriyaphap T, Patil AP, Temperley WH, et al. The dominant Anopheles vectors of human malaria in the AsiaPacific region: occurrence data, distribution maps and bionomic précis. Parasit Vectors. 2011;4:89.

12. Kanojia PC, Shetty PS, Geevarghese G. A long-term study on vector abundance \& seasonal prevalence in relation to the occurrence of Japanese encephalitis in Gorakhpur district, Uttar Pradesh. Indian J Med Res. 2003;117:104-10.

13. Mourya D, Ilkal M, Mishra A, Jacob PG, Pant U, Ramanujam S, et al. Isolation of Japanese encephalitis virus from mosquitoes collected in Karnataka State, India from 1985 to 1987. Trans R Soc Trop Med Hyg. 1989:83:550-2

14. Zhang $\mathrm{H}$. The natural infection rate of mosquitoes by Japanese encephalitis B virus in Yunnan Province. Chinese J Preventive Med. 1990;24:265-7.

15. Nguyen DM, Tran DH, Harbach RE, Elphick J, Linton YM. A new species of the Hyrcanus Group of Anopheles, subgenus Anopheles, a secondary vector of malaria in coastal areas of southern Vietnam. J Am Mosq Control Assoc. 2000;16:189-98.

16. Nguyen T. Malaria in Vietnam. Environment, prevention and treatment. Bull Soc Pathol Exot. 1992;86:494-9. 
17. Alam MS, Khan MG, Chaudhury N, Deloer S, Nazib F, Bangali AM, et al. Prevalence of anopheline species and their Plasmodium infection status in epidemic-prone border areas of Bangladesh. Malar J. 2010;9:15.

18. Shaoqing Z, Feng C, Webber R. A successful control programme for lymphatic filariasis in Hubei, China. Trans R Soc Trop Med Hyg. 1994;88:510-2.

19. Yang XS, Fang TZ, Chen DH, Cai GY, Li MS, Geng RG. Preliminary field trials of Romanomermis jingdeensis against Anopheles sinensis in the suburbs of Shanghai. Chin Med J (Engl). 1984;97:609-12.

20. Gao Q, Beebe NW, Cooper RD. Molecular identification of the malaria vectors Anopheles anthropophagus and Anopheles sinensis (Diptera: Culicidae) in central China using polymerase chain reaction and appraisal of their position within the Hyrcanus group. J Med Entomol. 2004;41:5-11.

21. Reid JA. Anopheline mosquitoes of Malaya and Borneo, vol. 31. Kuala Lumpur: Government of Malaysia, Institute for Medical Research Malaysia; 1968.

22. Harrison BA, Scanlon JE. Medical entomology studies-II The subgenus Anopheles in Thailand (Diptera: Culicidae). Contrib Am Entomol Inst. 1975;12:1-307.

23. Hempolchom C, Otsuka Y, Baimai V, Thongsahuan S, Saeung A, Taai K, et al. Development of a multiplex PCR assay for the identification of eight species members of the Thai Hyrcanus Group (Diptera: Culicidae). Appl Entomol Zool. 2013:48:469-76.

24. Rattanarithikul R, Harrison BA, Harbach RE, Panthusiri P, Coleman RE, Panthusiri P. Illustrated keys to the mosquitoes of Thailand IV Anopheles. Southeast Asian J Trop Med Public Health. 2006;37(Suppl2):1-128.

25. Choochote W. Evidence to support karyotypic variation of the mosquito, Anopheles peditaeniatus in Thailand. J Insect Sci. 2011:11:10.

26. Rattanarithikul R, Konishi E, Linthicum KJ. Detection of Plasmodium vivax and Plasmodium falciparum circumsporozoite antigen in anopheline mosquitoes collected in southern Thailand. Am J Trop Med Hyg 1996;54:114-21.

27. Saeung A, Hempolchom C, Baimai V, Thongsahuan S, Taai K, Jariyapan N, et al. Susceptibility of eight species members in the Anopheles hyrcanus group to nocturnally subperiodic Brugia malayi. Parasit Vectors. 2013;6:5

28. Paredes-Esquivel C, Donnelly MJ, Harbach RE, Townson H. A molecular phylogeny of mosquitoes in the Anopheles barbirostris Subgroup reveals cryptic species: implications for identification of disease vectors. Mol Phylogenet Evol. 2009;50:141-51.

29. Joshi D, Park MH, Saeung A, Choochote W, Min GS. Multiplex assay to identify Korean vectors of malaria. Mol Ecol Resour. 2010;10:748-50.

30. Li C, Wilkerson RC. Intragenomic rDNA ITS2 variation in the neotropical Anopheles (Nyssorhynchus) albitarsis complex (Diptera: Culicidae). J Hered. 2007;98:51-9.

31. Norris DE. Genetic markers for study of the anopheline vectors of human malaria. Int J Parasitol Parasites Wildl. 2002;32:1607-15.

32. Young I, Coleman AW. The advantages of the ITS2 region of the nuclear rDNA cistron for analysis of phylogenetic relationships of insects: a Dros ophila example. Mol Phylogenetics Evol. 2004;30:236-42.

33. Department of Disease Control (DDC). Thailand Malaria Elimination Program. Ministry of Public Health, Nonthaburi, Thailand. 2017. http://203.157.41.215/malariaR10/index_newversion.php. Accessed 11 Oct 2017.

34. Poolphol P, Harbach RE, Sriwichai P, Aupalee K, Sattabongkot J, Kumpitak C, et al. Natural Plasmodium vivax infections in Anopheles mosquitoes in a malaria endemic area of northeastern Thailand. Parasitol Res. 2017;116:3349-59.

35. Van Bortel W, Trung HD, le Thuan K, Sochantha T, Socheat D, Sumrandee $C$, et al. The insecticide resistance status of malaria vectors in the Mekong region. Malar J. 2008;7:102.

36. Chareonviriyaphap T, Aum-aung B, Ratanatham S. Current insecticide resistance patterns in mosquito vectors in Thailand. Southeast Asian J Trop Med Public Health. 1999;30:184-94.

37. Sumarnrote A, Overgaard HJ, Marasri N, Fustec B, Thanispong K, Chareonviriyaphap T, et al. Status of insecticide resistance in Anopheles mosquitoes in Ubon Ratchathani Province, northeastern Thailand. Malar J. 2017;16:299.

38. Marasri N, Overgaard HJ, Sumarnrote A, Thanispong K, Corbel V, Chareonviriyaphap T. Abundance and distribution of Anopheles mosquitoes in a malaria endemic area along the Thai-Lao border. J Vector Ecol. 2017:42:325-34.
39. Service MW. Mosquito ecology: field sampling methods. London-New York: Elsevier Applied Science; 1993.

40. WHO. Test procedures for insecticide resistance monitoring in malaria vector mosquitoes. Geneva: World Health Organization; 2016. http:// apps.who.int/iris/bitstream/10665/250677/1/9789241511575-eng.pdf. Accessed 10 Jan 2016.

41. Linton YM, Harbach RE, Seng CM, Anthony TG, Matusop A. Morphological and molecular identity of Anopheles (Cellia) sundaicus (Diptera: Culicidae), the nominotypical member of a malaria vector species complex in Southeast Asia. Syst Entomol. 2001;26:357-66.

42. Manguin $S$, Kengne $P$, Sonnier $L$, Harbach R, Baimai $V$, Trung $H$, et al. SCAR markers and multiplex PCR-based identification of isomorphic species in the Anopheles dirus complex in Southeast Asia. Med Vet Entomol. 2002;16:46-54.

43. Hall TA. Biological sequence alignment editor software. 2017. http://www. mbio.ncsu.edu/BioEdit/bioedit.html. Accessed 5 Jan 2017.

44. Gingrich JB, Weatherhead A, Sattabongkot J, Pilakasiri C, Wirtz RA. Hyperendemic malaria in a Thai village: dependence of year-round transmission on focal and seasonally circumscribed mosquito (Diptera: Culicidae) habitats. J Med Entomol. 1990;27:1016-26.

45. Sugiarto K, Hadi U, Soviana S, Hakim L. Confirmation of Anopheles peditaeniatus and Anopheles sundaicus as malaria vectors (Diptera: Culicidae) in Sungai Nyamuk Village, Sebatik Island North Kalimantan, Indonesia using an enzyme-linked immunosorbent assay. J Med Entomol. 2016;53:1422-4.

46. St Laurent B, Oy K, Miller B, Gasteiger EB, Lee E, Sovannaroth S, et al. Cowbaited tents are highly effective in sampling diverse Anopheles malaria vectors in Cambodia. Malar J. 2016;15:440.

47. Ritthison W, Tainchum K, Manguin S, Bangs MJ, Chareonviriyaphap T. Biting patterns and host preference of Anopheles epiroticus in Chang Island, Trat Province, eastern Thailand. J Vector Ecol. 2014:39:361-71.

48. Gunathilaka N, Denipitiya T, Hapugoda M, Abeyewickreme W, Wickremasinghe R. Determination of the foraging behaviour and blood meal source of malaria vector mosquitoes in Trincomalee District of Sri Lanka using a multiplex real time polymerase chain reaction assay. Malar J. 2016;15:242.

49. Obsomer V, Defourny P, Coosemans M. The Anopheles dirus complex: spatial distribution and environmental drivers. Malar J. 2007;6:26.

50. Trung HD, Bortel WV, Sochantha T, Keokenchanh K, Briet OJ, Coosemans M. Behavioural heterogeneity of Anopheles species in ecologically different localities in Southeast Asia: a challenge for vector control. Trop Med Int Health. 2005;10:251-62.

51. Kar NP, Kumar A, Singh OP, Carlton JM, Nanda N. A review of malaria transmission dynamics in forest ecosystems. Parasit Vectors. 2014;7:265.

52. Ngom EHM, Ndione JA, Ba Y, Konaté L, Faye O, Diallo M, et al. Spatio-temporal analysis of host preferences and feeding patterns of malaria vectors in the sylvo-pastoral area of Senegal: impact of landscape classes. Parasit Vectors. 2013;6:332

53. Chaumeau V, Fustec B, Nay Hsel S, Montazeau C, Naw Nyo S, Metaane $S$, et al. Entomological determinants of malaria transmission in Kayin state, eastern Myanmar: a 24-month longitudinal study in four villages. Wellcome Open Res. 2019:3:109.

54. Yasuoka J, Levins R. Impact of deforestation and agricultural development on anopheline ecology and malaria epidemiology. Am J Trop Med Hyg. 2007;76:450-60.

55. Feng $X$, Zhang S, Huang F, Zhang L, Feng J, Xia Z, et al. Biology, bionomics and molecular biology of Anopheles sinensis Wiedemann 1828 (Diptera: Culicidae), main malaria vector in China. Front Microbiol. 2017:8:1473.

56. Zhu G, Xia H, Zhou H, Li J, Lu F, Liu Y, et al. Susceptibility of Anopheles sinensis to Plasmodium vivax in malarial outbreak areas of central China. Parasit Vectors. 2013;6:176.

57. Somboon P, Suwonkerd W, Lines J. Susceptibility of Thai zoophilic Anophelines and suspected malaria vectors to local strains of human malaria parasites. Southeast Asian J Trop Med Public Health. 1994;25:766-70.

58. Rongsriyam Y, Jitpakdi A, Choochote W, Somboon P, Tookyang B, Suwonkerd W. Comparative susceptibility of two forms of Anopheles sinensis Wiedemann 1828 (Diptera: Culicidae) to infection with Plasmodium falciparum, P vivax, Pyoelii and the determination of misleading factor for sporozoite identification. Southeast Asian J Trop Med Public Health. 1998;29:159-67. 
59. Nwane P, Etang J, Chouaïbou M, Toto JC, Koffi A, Mimpfoundi R, et al. Multiple insecticide resistance mechanisms in Anopheles gambiae sl populations from Cameroon. Central Africa. Parasit Vectors. 2013;6:41.

60. Matowo J, Kulkarni MA, Mosha FW, Oxborough RM, Kitau JA, Tenu F, et al Biochemical basis of permethrin resistance in Anopheles arabiensis from Lower Moshi, north-eastern Tanzania. Malar J. 2010;9:193.

61. Chaumeau V, Cerqueira D, Zadrozny J, Kittiphanakun P, Andolina C, Chareonviriyaphap T, et al. Insecticide resistance in malaria vectors along the Thailand-Myanmar border. Parasit Vectors. 2017:10:165.

62. Singh OP, Dykes $\mathrm{CL}$, Lather M, Agrawal OP, AdakT. Knockdown resistance $(k d r)$-like mutations in the voltage-gated sodium channel of a malaria vector Anopheles stephensi and PCR assays for their detection. Malar J. 2011;10:59.
63. Verhaeghen K, Van Bortel W, Trung HD, Sochantha T, Keokenchanh K, Coosemans M. Knockdown resistance in Anopheles vagus, An sinensis, An paraliae and An peditaeniatus populations of the Mekong region. Parasit Vectors. 2010;3:59.

\section{Publisher's Note}

Springer Nature remains neutral with regard to jurisdictional claims in published maps and institutional affiliations.
Ready to submit your research? Choose BMC and benefit from:

- fast, convenient online submission

- thorough peer review by experienced researchers in your field

- rapid publication on acceptance

- support for research data, including large and complex data types

- gold Open Access which fosters wider collaboration and increased citations

- maximum visibility for your research: over 100M website views per year

At BMC, research is always in progress.

Learn more biomedcentral.com/submissions 